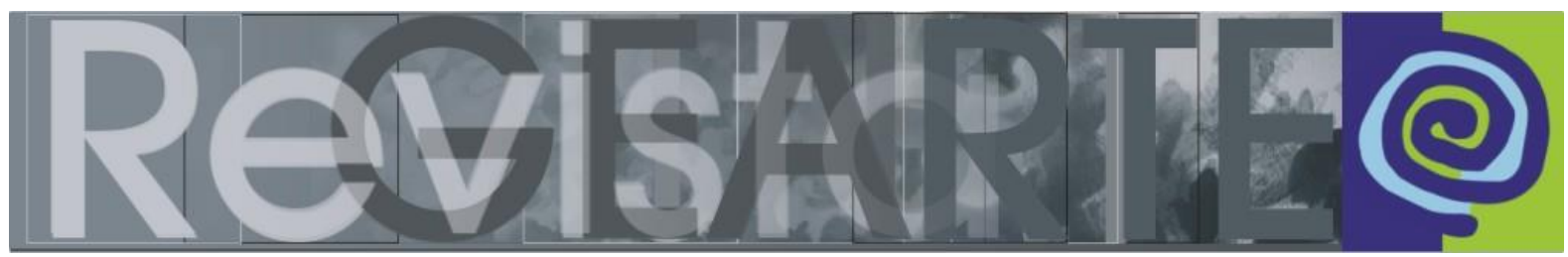

e-ISSN 2357-9854

\title{
Uma cartografia sobre o Ensino das Artes Visuais na BNCC entre 2014-2018
}

\author{
Maria Emília Sardelich (Universidade Federal da Paraíba \\ — UFPB, João Pessoa/PB, Brasil) \\ Guilherme Panho (Universidade Federal da Paraíba \\ — UFPB, João Pessoa/PB, Brasil)
}

\begin{abstract}
RESUMO - Uma cartografia sobre o Ensino das Artes Visuais na BNCC entre 2014-2018 - Este artigo apresenta uma cartografia sobre o Ensino das Artes Visuais na Base Nacional Comum Curricular (BNCC), entre 2014 e 2018. A BNCC insere-se nas políticas curriculares que ultrapassa seus domínios, sendo representada como uma reforma educacional. Os aspectos mais destacados vinculam-se ao contexto de produção do documento, enfatizando a desvalorização da Arte nessa política curricular frente a já conquistada demarcação como conhecimento em políticas anteriores, o que demandou um amplo movimento de resistência de artistas e educadores. Os resultados apontam para uma ausência de dissertações e teses que discutam essa política curricular para o Ensino das Artes Visuais cotejando as várias versões do documento, indicando suas continuidades e descontinuidades em virtude dos projetos educacionais em disputa.
\end{abstract}

PALAVRAS-CHAVE

Política educacional. Política curricular. Ensino das Artes Visuais. BNCC.

RESUMEN - Una cartografía sobre la Enseñanza de las Artes Visuales en la BNCC entre 20142018 - Este artículo presenta una cartografía sobre la Enseñanza de las Artes Visuales en la Base Nacional Común Curricular (BNCC), entre 2014 y 2018. La BNCC se inserta en las políticas curriculares que sobrepasa sus dominios, siendo representada como una reforma educativa. Los aspectos más destacados se vinculan al contexto de producción del documento, enfatizando la desvalorización del Arte en esa política curricular frente a la ya conquistada demarcación como conocimiento en políticas anteriores, lo que demandó un amplio movimiento de resistencia de artistas y educadores. Los resultados apuntan a una ausencia de disertaciones y tesis que discutan esa política curricular para la Enseñanza de las Artes Visuales comparando las varias versiones del documento, indicando sus continuidades y discontinuidades en virtud de los proyectos educativos en disputa.

PALABRAS CLAVE

Política educativa. Política curricular. Enseñanza de las Artes Visuales. BNCC.

\section{INTRODUÇÃO}

Este artigo se inscreve na área da política educacional, compreendendo-a como campo que estuda os problemas que cercam a educação, tanto as demandas da população, bem como as ações do Estado para equacioná-las, neste caso a política curricular para o Ensino das Artes Visuais manifesta na Base Nacional Comum Curricular (BNCC). Tem por objetivo apresentar uma cartografia da discussão sobre as Artes Visuais na BNCC, do Brasil, entre os anos de 2014 e 2018, a fim de identificar

\footnotetext{
SARDELICH, Maria Emília; PANHO, Guilherme.

Uma cartografia sobre o Ensino das Artes Visuais na BNCC entre 2014-2018.

Revista GEARTE, Porto Alegre, v. 5, n. 2, p. 232-244, maio/ago. 2018.

http://dx.doi.org/10.22456/2357-9854.83395
} 
as produções bibliográficas que analisam esse ensino no documento, destacando os aspectos enfatizados pelos pesquisadores.

De acordo com a definição geográfica, a cartografia expressa os aspectos de uma superfície ou paisagem, o que inclui o posicionamento do próprio cartógrafo nessa paisagem. O olhar do cartógrafo constrói uma possibilidade de paisagem, posto que sua função é "dar passagem, fazer passagem, ser passagem" (COSTA, 2014, p. 75). Oliveira e Mossi (2014) entendem a cartografia como um conjunto metodológico, não decidido a priori, que vai se inventando no decorrer da caminhada em virtude das necessidades do relevo do percurso.

Partindo desses pressupostos, compreendemos que atuamos sobre a matéria a ser cartografada, pois a cartografia sinaliza que as questões que fazemos aos territórios de pesquisa se elaboram na medida em que "estabelecemos relações com aquilo que nos faz questionar" (COSTA, 2014, p. 73), que produzem deslocamentos de ideias naturalizadas. Pretendemos dar passagem ao quem e que escreveu sobre o Ensino das Artes Visuais na BNCC em busca de espaços de interlocução. O mapeamento que apresentamos explorou a Biblioteca Digital Brasileira de Teses e Dissertações (BDTD), do Instituto Brasileiro de Ciência e Tecnologia (IBICT) e periódicos das áreas de Artes e Educação. Justificamos a escolha pela BDTD do IBICT pelo fato de disponibilizar os trabalhos completos produzidos em programas de pós-graduação do País. Estes são indicadores de avaliação da produção científica de uma área, sendo possível localizar as lacunas de pesquisa (MORAES; OLIVEIRA, 2010). O recorte temporal delimitou o ano de 2014 pelo fato da homologação da Lei no 13.005/ 2014, que aprovou o Plano Nacional de Educação (PNE) 2014-2024, impulsionar a elaboração da BNCC. Compreendemos que a discussão que vamos focalizar está em movimento e que esta cartografia pode conter omissões, apesar da busca atenta nas bases de dados.

Organizamos os achados do seguinte modo: uma demarcação dos campos da política educacional e curricular, seguida de uma apresentação do documento, o levantamento bibliográfico realizado e, por fim, as considerações alcançadas até o momento. 


\section{Políticas Educacionais e Políticas Curriculares}

O vocábulo política refere-se ao exercício de alguma forma de poder e às consequências desse exercício. Compreendemos o poder como uma "rede produtiva que atravessa todo o corpo social" (FOUCAULT, 1979, p. 9), uma rede de relações que se forma a partir dos posicionamentos relativos dos sujeitos nessa rede de modo a influenciar o comportamento de outras pessoas. O poder "permeia, produz coisas, induz ao prazer, forma saber, produz discurso" (FOUCAULT, 1979, p. 9). Desse modo, os atos políticos possuem aspectos indissociáveis como: o interesse - a partir de determinado posicionamento ético, financeiro, religioso, entre outros possíveis - e a decisão, que poderá ser negociada, consensual, majoritária, imposta. Portanto, compreendemos as políticas como "processo através do qual interesses são transformados em objetivos e os objetivos são conduzidos à formulação e tomada de decisões efetivas" (RIBEIRO, 1998, p. 11). Queiramos ou não, estamos imersos nas políticas, pois torna-se impossível "pensar, sequer, a educação, sem que se esteja atento à questão do poder" (FREIRE, 1989, p. 26). Logo, se as políticas não oferecem "oportunidades de educação para pessoas como nós, é evidente que esse processo nos prejudica e, paralelamente, beneficia e privilegia outros" (RIBEIRO, 1998, p. 17).

As políticas são práticas coletivas que carregam posicionamentos diversos, pois grupos não hegemônicos também produzem políticas, mesmo que estas não sejam visíveis para aqueles que as analisam a partir de um construído modo de ver "o que é hegemônico com o que aprenderam com o modo de pensar hegemônico (ALVES, 2010, p. 49). Para Mainardes (2018) as políticas educacionais são respostas, "atos do Estado" para atender problemas e demandas da população. Costumam ser pontuais, incompletos e se constituem em instrumentos de poder simbólico, expressos em textos legais ou discursos oficiais que podem gerar "hierarquias, aumentar desigualdades, beneficiar alguns grupos e excluir outros" (MAINARDES, 2018, p. 188).

Parte integrante das políticas educacionais, as políticas curriculares são tomadas de decisão sobre o desenvolvimento do currículo escolar. Constituem o "conhecimento escolar: um conhecimento construído simultaneamente para a escola 
(em ações externas à escola) e pela escola (em suas práticas institucionais cotidianas)" (LOPES, 2004, p. 112). Cóssio (2014) adverte que qualquer projeto curricular remete a um projeto educacional no qual se encontram projetos de sociedade em disputa. O projeto de sociedade neoliberal globalizada tem tornado cada vez mais evidente o distanciamento entre ricos e pobres, bem como a submissão destes àqueles, interferindo nas decisões econômicas, políticas e sociais. Destaca as dificuldades para identificar os projetos societários em disputa, geralmente nomeados como conservadores e progressistas ou democráticos, pois conceitos como cidadania, igualdade, entre outros, são utilizados pelos conservadores com a finalidade de buscar o consenso em torno de suas visões de mundo.

Cóssio (2014) afirma que o ideário neoliberal assumido pelo Brasil, desde a década de 1990, contou com o apoio de organismos internacionais, como o Banco Mundial (BM). As reformas educacionais da década de 1990 acompanharam a lógica produtivista, porém a partir dos anos 2000 o BM alterou suas recomendações, indicando políticas de alívio à pobreza, sem abandonar a visão econômica, incentivando políticas distributivas para cobrir carências básicas da população. Essas políticas não atuam nas causas da pobreza, mas amenizam seus efeitos, com o intuito de manter o projeto capitalista despolitizando a política, apagando fronteiras entre esquerda e direita, público e privado, fundamentado na ideia de governança que inclui o governo e a sociedade civil assumindo responsabilidades do setor público. A partir dessas recomendações, construiu-se no Brasil da primeira década do século XXI um cenário que ampliou o acesso educacional de grupos historicamente excluídos da escola brasileira. Nesse sentido, as Diretrizes Curriculares Nacionais para a Educação Básica, Resolução CNE/CEB nำ4/2010, contemplam as linhas reguladoras da organização curricular de todas as redes de ensino.

A Resolução CNE/CEB no 4/2010 indica, no artigo 14, a base nacional comum da Educação Básica (EB) e no 27, as várias modalidades da EB. Cada etapa da EB e modalidade foi contemplada com uma Diretriz específica que considera grupos sociais historicamente excluídos da escola brasileira. Apesar de essas Diretrizes expressarem a base nacional comum e sinalizarem a preocupação com a inclusão de grupos historicamente excluídos, o projeto pela padronização curricular em torno de 
um documento ganhou corpo nos discursos conservadores em torno da melhoria do Índice da Educação Básica (IDEB). Essa pressão produz uma relação inversa entre currículo e avaliação, colocando "a avaliação pautando o currículo, e não o contrário, as provas avaliando a qualidade do currículo" (CÓSSIO, 2014, p. 1582).

\section{A Base Nacional Comum Curricular}

É a partir da LDBEN que a expressão "base nacional comum" ganha notoriedade, pois o artigo 26 menciona que os currículos do Ensino Fundamental (EF) e Ensino Médio (EM) deveriam ter tal base. A LDBEN também utiliza "base nacional comum do currículo", no artigo 38 , referente aos exames supletivos e "base comum nacional", no artigo 64, referente à formação dos profissionais de educação. A partir da inserção dessas expressões, que não são sinônimas, Alves (2014) destaca que inúmeras forças econômicas e sociais pressionaram para a elaboração dessa base que resultou na tentativa de implantação dos Parâmetros Curriculares Nacionais (PCNs). A autora nota que, na época, também circulou o discurso da premente "necessidade educacional" em torno dos parâmetros com milhares de reais gastos em ações de formação para sua adoção. Nesse avassalador processo também se implantou um sistema de avaliação de estudantes e escolas através de provas nacionais.

Entre 2006 e 2013 a discussão em torno dessa base comum se concentrou na formulação das Diretrizes Curriculares Nacionais Gerais para a EB (BRASIL, 2013). A homologação da Lei no 13.005/2014, que aprovou o PNE, introduziu a expressão objetivos de aprendizagem e desenvolvimento estabelecendo que estes deveriam ser apresentados para cada ano escolar. Essa exigência pressupôs um arcabouço mais rígido e reforçou a pressão para um novo documento (BRASIL, 2017b).

A versão preliminar da BNCC foi elaborada por um comitê assessor e uma equipe de especialistas, formada por professores universitários que atuavam em cursos de licenciatura, professores da escola de EB e técnicos das Secretarias de Educação, indicados pelo Conselho Nacional de Secretários de Educação (CONSED) e pela União dos Dirigentes Municipais de Educação (UNDIME). Procurou definir os componentes curriculares básicos a partir dos denominados "direitos de 
aprendizagem" que possibilitariam definir os objetivos de aprendizagem. Nessa versão os objetivos de aprendizagem indicam as ações dos sujeitos a partir da apropriação de conteúdos curriculares, ou seja, contempla o "ensino por competências". Após uma consulta pública, em março de 2016, uma segunda versão evidenciou a multiplicidade de vozes que argumentaram em favor das conquistas que já constavam nas Diretrizes da EB. Com o golpe parlamentar de 2016, que afastou a presidenta eleita Dilma Vana Rousseff de seu segundo mandato (2015-2018), o MEC foi entregue à coligação liberal-conservadora (FREITAS, 2017) e a discussão do documento ficou sob comando do Movimento pela Base Nacional Comum, restringindo o comitê de assessores e especialistas das várias áreas do conhecimento. Em uma consulta ao website do Movimento pela Base Nacional Comum ${ }^{1}$ é possível conferir os apoiadores da BNCC, as Fundações ${ }^{2}$ que "atuam como um verdadeiro partido: com programa, metas, estruturas de sustentação, lideranças" (SANTOS, 2016, s.p.).

A terceira versão, publicada em abril de 2017, diferentemente da versão anterior, é sucinta e afirma seu alinhamento com organismos internacionais como a Organização para a Cooperação e Desenvolvimento Econômico (OCDE), que coordena o Programa Internacional de Avaliação de Alunos (PISA), (BRASIL, 2017a, p. 16). O documento homologado, por meio da Resolução CNE/CP $n^{\circ}$ 2/2017, foi mais uma vez recortado e oferece um conjunto de descritores "codificados" com as habilidades esperadas e, supostamente, passíveis de serem testadas. Desse modo, a BNCC impõe a matriz de referência para regular todas as etapas da EB pela avaliação em larga escala.

\section{O Ensino das Artes Visuais na BNCC}

Realizamos a exploração na BDTD do IBICT, a partir dos descritores BNC -por ser esta uma das siglas para referir-se incialmente ao documento- BNCC, Arte e Artes Visuais, presentes no título, resumo ou palavras-chave dos mesmos, finalizando a

1 Disponível em: http://movimentopelabase.org.br

2 Pessoa jurídica autônoma destinada a fins de utilidade pública ou de beneficência, mediante dotação especial de bens livres. 
consulta em maio de 2018. O cruzamento dos descritores BNC e Arte, localizou 14 resultados, porém desses somente um trabalho (SENA, 2016) utiliza a sigla BNC referindo-se ao documento, os demais situam-se em outras áreas do conhecimento com significados como Baixo Nível de Competitividade (BNC), entre outros. A dissertação de Sena (2016) não analisa a BNC ou BNCC, mas somente refere-se à elaboração da base como um instável cenário de mudanças no currículo das escolas de EB e tem por objetivo investigar como professores com formação superior em Música organizam o conteúdo da rede pública de do Distrito Federal (DF). O autor utiliza a sigla BNCC em sua lista de abreviaturas e no momento de sua problematização refere-se à BNC (SENA, 2016, p. 17). Ao cruzar os descritores BNC e Artes Visuais, a base de dados indicou 3 resultados, sendo que dois utilizam a sigla com outros significados e um é o mesmo indicado no cruzamento anterior (SENA, 2016), que aponta as Artes Visuais como uma das linguagens do componente curricular Arte, porém não examina suas especificidades.

O descritor BNCC apresenta 40 resultados, sendo que somente 28 referem-se à discussão do documento em estudo, nos demais a sigla refere-se a outras áreas. Dos 28 que atendem aos nossos critérios, 3 focalizam o processo de elaboração da BNCC e 1 o processo de implementação dessa política. Os demais 24 trabalhos discutem os componentes curriculares, sendo $4 \mathrm{em}$ Matemática, 2 em Língua Portuguesa, 2 em Línguas Estrangeiras, 2 em Língua Brasileira de Sinais, 2 em Educação Ambiental, 2 em Ciências para o EF, 2 em Tecnologias, Mídias Sociais e Digitais, 1 em História, 1 em Geografia, 1 em Educação do Campo, 1 em Educação das Relações Étnico Raciais, 1 em Formação de Professores e 3 em Arte. Os 3 trabalhos referentes ao componente curricular Arte são os de Sena (2016), já classificado nos descritores anteriores, Alves (2017) e Diniz (2017).

Foram encontrados 21 resultados adequados aos critérios de busca no cruzamento dos descritores BNCC e Arte, todos já listados nos cruzamentos anteriores, inclusive os dois trabalhos referentes ao componente curricular Arte: Sena (2016) e Alves (2017). O cruzamento BNCC e Artes Visuais apresenta 13 resultados, todos já classificados nos cruzamentos anteriores e o único do componente curricular Arte é o de Sena (2016). 
Os três trabalhos que se referem à Arte na BNCC apenas mencionam as Artes Visuais como linguagem do componente curricular, porém suas análises recaem sobre a Música (SENA, 2016), Artes Cênicas (ALVES, 2017) e a Dança no EM (DINIZ, 2017). Até o momento do término deste levantamento não foi encontrado na BDTD do IBICT nenhum trabalho que discuta as Artes Visuais na BNCC.

Prosseguimos explorando periódicos das áreas de Artes e Educação com os mesmos descritores e critérios, localizando 8 resultados: Barbosa (2016, 2017a, 2017b), Carvalho (2016), Gabre (2016), lavelberg (2018), Romanelli (2016) e Peres (2017). Barbosa (2016) considera que a Arte foi menosprezada na versão inicial da BNCC ao ser tratada como subcomponente curricular. Destaca que a denominação fere direitos conquistados em legislações anteriores. Apesar de não analisar a BNCC, Barbosa (2017a, 2017b) volta a referir-se ao contexto de produção do documento, ao período entre a segunda e terceira versão, momento da edição da Medida Provisória (MP) no 746, de 2016, posteriormente convertida na Lei no 13.415/2017 que alterou a redação da LDBEN. Essa MP pretendia restringir o Ensino da Arte à El e EF. Contra essa restrição, a autora apresenta argumentos baseados nas pesquisas do professor James Catterall, da Universidade da Califórnia (UCLA), em Los Angeles, Estados Unidos, sobre o efeito das atividades artísticas na cognição. As produções de Barbosa (2016, 2017a, 2017b) soam reiterativas frente a já conquistada demarcação da Arte em 1996, fruto de um intenso esforço de artistas e educadores ao longo de todo o século XX no Brasil, porém esta foi ameaçada pela coligação liberal-conservadora na condução da política educacional do MEC pós golpe parlamentar de 2016, o que demandou um novo movimento de resistência de artistas e educadores a essa política.

Gabre (2016) coteja a primeira versão da BNCC com o Referencial Curricular Nacional para a Educação Infantil (RCNEI), de 1998, as Diretrizes Curriculares Nacionais para a Educação Infantil (DCNEI), de 2009. Identifica como avanço a disposição curricular da primeira versão da BNCC, pelo fato desta não se organizar por áreas de conhecimento, mas sim por campos de experiências. Destaca que esse arranjo curricular propõe a experiência das crianças como ponto de partida para a organização do currículo, sendo mais próximo da arte contemporânea. Pondera que apesar desse arranjo, os objetivos de aprendizagem, principalmente no campo 
Traços, Sons, Cores, Formas e Cores, remetem a situações de aprendizagem que o próprio documento indica pretender superar.

Peres (2017) discute o componente curricular Arte na BNCC, apresentando as demandas das associações de arte-educadores. Aponta como a primeira versão ocasionou um alerta entre os profissionais, pois tanto a expressão subcomponente curricular como a inserção na área de Linguagens indicava a perda de posição como área de conhecimento. Relata que esse fato provocou a mobilização dos arteeducadores. O ofício n 6/2015, da Federação de Arte-Educadores do Brasil, firmado com demais associações da área, foi enviado ao MEC com várias demandas, dentre estas a constituição de uma área de Arte, desvinculada da área de Linguagens, tornando-a autônoma e que fosse explicitada a atuação do professor com formação específica em cada componente curricular da área de Arte.

Romanelli (2016) analisa a segunda versão da BNCC enfatizando as particularidades do ensino da Música. Indica como avanço o fato de o documento assumir a necessidade do professor formado nas especificidades de cada uma das linguagens. Contudo, não perde de vista a realidade contraditória do componente curricular englobar quatro linguagens e ser atribuído a um único professor que deve abordar todas. Conclui que, se de um lado se preserva a especificidade das linguagens artísticas, por outro se fragiliza o ensino ao exigir que a atividade docente ocorra sem o domínio da área.

Carvalho (2016) analisa a segunda versão da BNCC com ênfase nas Artes Visuais. Indica que essa versão acena para as dimensões de conhecimentos simultâneos, como: criação, crítica, estesia, expressão, fruição e reflexão. 0 documento afirma que essas dimensões não são categorias, mas linhas maleáveis, o que leva a autora interpretar que o documento sugere a ideia de linhas que dialogam, tão presentes no processo artístico. Considera que o documento assume um viés rizomático, sinalizando um indicador metodológico. Percebe fragilidades em relação ao arcabouço teórico que, segundo a autora, deveria ser mais explicitado nas versões posteriores, pois esses aspectos incluem as práticas docentes e a clareza de onde se fala possibilita ao professor "fazer suas escolhas e considerar diante do que atua o 
que deseja ou não" (CARVALHO, 2016, p. 510). Posiciona-se afirmando que no conturbado século $\mathrm{XXI}$, com intensos movimentos migratórios, de relações econômicas fragilizadas, questões políticas desmoralizadas, é necessário pensar o currículo, porém "as certezas não cabem mais a um documento deste porte, mas sim a abertura para que os sujeitos se encontrem nele e a partir dele possam fazer suas escolhas" (CARVALHO, 2016, p. 519).

lavelberg (2018) analisa as Artes Visuais na terceira versão da BNCC buscando continuidades e descontinuidades existentes entre esse documento e os PCNs. A autora considera continuidade os aspectos que foram preservados ou derivados dos PCNs na BNCC e descontinuidade o que "foi inovado e abandonado na Base em relação às concepções dos Parâmetros" (IAVELBERG, 2018, p. 74). A presença da Arte na área de Linguagens é apontada pela autora como uma descontinuidade em relação aos PCNs, o que denota uma desvalorização do componente curricular na EB que também está excluído das avaliações dos sistemas de ensino. Destaca que a estrutura dos documentos se diferencia, pois, a BNCC não explicita os eixos de aprendizagem como os PCNs, indicados como fazer, fruir e refletir, que podem se relacionar às dimensões do conhecimento na BNCC. Entende que essas dimensões do conhecimento explicitadas na BNCC podem ser colocadas paralelamente aos eixos dos PCNs, aproximando o eixo fazer com as dimensões criação e expressão; o eixo expressão com estesia e fruição; o eixo refletir como crítica e reflexão. A autora aponta como descontinuidade a codificação das habilidades e compreende que estas não podem ser aprendidas sem os conteúdos. Conclui que novas propostas podem se instalar nas descontinuidades e que é nas diferenças entre os documentos que poderia residir uma atualização em relação à realidade educacional contemporânea do País.

\section{Considerações transitórias}

Como cartógrafos/arte/educadores também fazemos parte da cartografia apresentada, pois participamos das políticas educacionais e curriculares, construindo o conhecimento escolar em nosso fazer cotidiano que pode deflagrar anuências, insurgências, resistências. Esta cartografia ressalta a preocupação dos pesquisadores 
com as demarcações da Arte na BNCC, sua localização na área de Linguagens, sua denominação como subcomponente curricular, a ingerência do setor privado no público, a mobilização e resistência dos arte-educadores contra o projeto conservador de padronização curricular, de regulação da Educação Básica por meio das avaliações em larga escala, facilitada pela imposição da matriz de referência de habilidades a serem testadas que constitui a atual BNCC.

Também nos encontramos com uma lacuna na produção dos Programas de Pós-graduação em Artes Visuais, que ainda não se debruçaram para cotejar as três versões do documento, as continuidades e descontinuidades presentes nessas versões, que revelam projetos educacionais em disputa, tanto pelo controle da gestão escolar, como também pelos objetivos, conteúdos, percursos formativos nos quais as Artes Visuais são relevantes, pois podem apresentar e fomentar a diversidade do e no campo do visível. É nesse encontro que pretendemos dar continuidade a esta cartografia em um próximo trabalho, aceitando o desafio de percorrer essa brecha pouco explorada, dando passagem às políticas não hegemônicas também presentes nesse território.

\section{Referências}

ALVES, Nilda. Sobre a possibilidade e a necessidade de uma base nacional comum. Revista ECurriculum, São Paulo, v.2, n.3, p.1464-1479, out. /dez. 2014.

ALVES, Nilda. Redes educativas "dentrofora" das escolas exemplificadas pela formação de professores. In: DALBEN, Ângela et al. (Org.). Convergências e tensões no campo da formação e do trabalho docente. Belo Horizonte: Autêntica, 2010. p. 49-66.

ALVES, Flávia Teodoro. Corpoarte: felicidade e resistência. 2017. 213 f. Dissertação (Mestrado em Artes) - Universidade Estadual Paulista, São Paulo, 2017. Disponível em: http://bdtd.ibict.br/vufind/Record/UNSP_0e632041a5289200be02434ae973bb6e Acesso em: 22 abr. 2018.

BARBOSA, Ana Mae. Políticas públicas para o ensino da arte no Brasil: o perde e ganha das lutas. Arte Educação On Line, 26 jan. 2016. Disponível em: http://www3.eca.usp.br/sites/default/files/form/ biblioteca/acervo/producao-academica/002791825.pdf Acesso em: 26 mai. 2018.

BARBOSA, Ana Mae. O Dilema das Artes no Ensino Médio no Brasil. Colégio Pedro II, Revista do Departamento de Desenho e Artes Visuais, Rio de Janeiro, v. 1, n.1, p. 6-11, 2017 a.

BARBOSA, Ana Mae. O dilema das Artes no Ensino Médio no Brasil. PÓs: Revista do Programa de Pós-graduação em Artes da EBA/UFMG. v. 7, n.13: mai.2017b.

BRASIL. Ministério da Educação. Base Nacional Comum Curricular. Brasília: MEC: abril 2017a.

BRASIL. Conselho Nacional de Educação. Parecer CNE/CP n. 15/2017. 2017b. 
BRASIL. Ministério da Educação. Diretrizes Curriculares Nacionais Gerais da Educação Básica. Brasília: MEC, SEB, DICEI, 2013.

CARVALHO, Carla. Uma reflexão acerca das artes visuais sobre a segunda versão da Base Nacional Comum Curricular. Linguagens: Revista de Letras, Artes e Comunicação, Blumenau, v. 10, n. 3, p. 502521, set./dez. 2016.

CÓSSIO, Maria de Fátima. Base Comum Nacional: uma discussão para além do currículo. Revista eCurriculum, São Paulo, v. 12, n. 3, p. 1570-1590, out./dez. 2014.

COSTA, Lucio Bedin da. Cartografia: uma outra forma de pesquisar. Revista Digital do LAV, Santa Maria, v. 7, n. 2, p. 66-77, mai./ago. 2014.

DINIZ, I. K. dos S. A dança no ensino médio: material didático apoiado pelas TIC. 2017. 358 f. Tese (Doutorado em Desenvolvimento Humano e Tecnologias) - Universidade Estadual Paulista, Rio Claro, 2017. Disponível em: http://bdtd.ibict.br/vufind/Record/UNSP_3c6babaec69cc9d0a052cf3bb59b3aa5 Acesso em: 22 abr. 2018

FOUCAULT, Michel. Microfísica do poder. 11. ed. Rio de Janeiro: Graal, 1997.

FREIRE, Paulo. A importância do ato de ler: três artigos que se completam. São Paulo: Cortez, 1989.

FREITAS, Luiz Carlos de. BNCC: uma base para o gerencialismo-populista. Blog do Freitas, 07 abr. 2017. Disponível em: <https://avaliacaoeducacional.com/2017/04/07/bncc-uma-base-para-ogerencialismo-populista/> Acesso em: 26 mai. 2018.

GABRE, Solange de Fátima. A arte na educação infantil: uma reflexão a partir dos documentos oficiais RCNEI - DCNEI - BNCC. Linguagens: Revista de Letras, Artes e Comunicação, Blumenau, v. 10, n. 3, p. 491-501, set./dez. 2016.

IAVELBERG, Rosa. A Base Nacional Curricular Comum e a formação dos professores de Arte. Horizontes, v. 36, n. 1, p. 74-84, jan./abr. 2018.

LOPES, Alice Casimiro. Políticas curriculares: continuidade ou mudança de rumos? Revista Brasileira de Educação, n. 26, p.109-118, ago. 2004.

MAINARDES, Jefferson. Reflexões sobre o objeto de estudo da política educacional. Laplage em Revista, Sorocaba, v.4, n. 1, p. 186-201, jan./abr. 2018.

MORAES, Alice Ferry de; OLIVEIRA, Telma Maria de. Experiências relacionadas ao levantamento de teses e dissertações. Informação \& Sociedade: Estudos, João Pessoa, v. 20, n.1, p. 73-81, jan./abr. 2010.

OLIVEIRA, Marilda O. de; MOSSI, Cristian P. Cartografia como estratégia metodológica: inflexões para pesquisa em educação. Conjecturas, Caxias do Sul, v. 19, n. 3, p. 185-198, set./dez. 2014.

PERES, José Roberto Pereira Peres. Questões atuais do Ensino de Arte no Brasil: O lugar da Arte na Base Nacional Comum Curricular. Colégio Pedro II, Revista do Departamento de Desenho e Artes Visuais, Rio de Janeiro, v. 1, n. 1, p. 24- 36, 2017.

RIBEIRO, João Ubaldo. Política: quem manda, por que manda, como manda. 3. ed. Rio de Janeiro: Nova Fronteira, 1999.

ROMANELLI, Guilherme Gabriel Ballande. Falando sobre a Arte na Base Nacional Comum CurricularBNCC- um ponto de vista da Educação Musical. Linguagens, Revista de Letras, Artes e Comunicação. v. 10, n. 3, p. 476- 490, 2016.

SANTOS, Marco Antônio. O "partido" das fundações empresariais que atuam na educação. Observatório na Mídia, 10 ago. 2016. Disponível em: http://www.epsjv.fiocruz.br/noticias/observatoriona-midia/passei-a-vida-toda-fugindo-de-politica-conta-lemann. Acesso em: 26 mai. 2018.

SENA, Ibsen Perucci de. A organização do conteúdo de Música no componente curricular Arte: dois estudos de caso com professores da rede pública de educação do DF. 2016. 182 f. Dissertação (Mestrado em Música em Contexto) - Universidade de Brasília, Brasília. 2016. Disponível em: http://bdtd.ibict.br/vufind/Record/UNB_3e621751813f1be3268a1e52e4e22cc3 Acesso em: 22 abr. 2018. 


\section{Maria Emilia Sardelich}

Doutora em Educação, professora da Universidade Federal da Paraíba (UFPB), Programa de PósGraduação em Artes Visuais (PPGAV/UFPB/UFPE). Atua na área de Didática e Ensino de Arte, cursos de Licenciatura, modalidades presenciais e a distância.

Email: emilisar@hotmail.com

Currículo: http://lattes.cnpq.br/8436767321723519

\section{Guilherme Panho}

Mestrando do Programa Associado de Pós-Graduação em Artes Visuais (PPGAV UFPB/UFPE), linha de Pesquisa Ensino das Artes Visuais no Brasil. Licenciado em Artes pela Universidade do Oeste de Santa Catarina (UNOESC). Atua na Educação Básica como Professor de Arte no Ensino Fundamental I e II.

Email: gpanho@yahoo.com

Currículo: http://lattes.cnpq.br/8058534144606970

Recebido em 31 de maio de 2018

Aceito em 3 de agosto de 2018

Uma cartografia sobre o Ensino das Artes Visuais na BNCC entre 2014-2018.

Revista GEARTE, Porto Alegre, v. 5, n. 2, p. 232-244, maio/ago. 2018.

Disponível em: http://seer.ufrgs.br/gearte 